\title{
PARTNER SELECTION OF STRATEGIC ALLIANCE FOR A LINER SHIPPING COMPANY USING EXTENT ANALYSIS METHOD OF FUZZY AHP
}

\author{
Ji-Feng Ding \\ Department of Aviation and Maritime Transportation Management, Chang Jung Christian University, Gui-Ren, Tainan \\ County 711, Taiwan, R.O.C., jfding@mail.cjcu.edu.tw
}

Follow this and additional works at: https://jmstt.ntou.edu.tw/journal

Part of the Business Commons

\section{Recommended Citation}

Ding, Ji-Feng (2009) "PARTNER SELECTION OF STRATEGIC ALLIANCE FOR A LINER SHIPPING COMPANY USING EXTENT ANALYSIS METHOD OF FUZZY AHP," Journal of Marine Science and Technology. Vol. 17: Iss. 2, Article 3. DOI: $10.51400 / 2709-6998.1963$

Available at: https://jmstt.ntou.edu.tw/journal/vol17/iss2/3

This Research Article is brought to you for free and open access by Journal of Marine Science and Technology. It has been accepted for inclusion in Journal of Marine Science and Technology by an authorized editor of Journal of Marine Science and Technology. 


\section{PARTNER SELECTION OF STRATEGIC ALLIANCE FOR A LINER SHIPPING}

COMPANY USING EXTENT ANALYSIS METHOD OF FUZZY AHP

\section{Acknowledgements}

This paper is partially based upon the result of the research sponsored by National Science Council of the Republic of China, under the project number of NSC96-2416-H-309-004. The author would like to thank three anonymous referees for their excellent comments and valuable advice in this paper. 


\section{PARTNER SELECTION OF STRATEGIC ALLIANCE FOR A LINER SHIPPING COMPANY USING EXTENT ANALYSIS METHOD OF FUZZY AHP}

\begin{abstract}
Key words: partner selection, strategic alliance, extent analysis method of fuzzy AHP.
\end{abstract}

Ji-Feng Ding*

\begin{abstract}
This paper applies the modified extent analysis method of fuzzy AHP approach for selecting suitable partners of strategic alliance for a liner shipping company. An empirical survey for selecting partners is studied to find out the most appropriate company based on the proposed fuzzy AHP algorithm. To facilitate the main issue for selecting a partner, a hierarchical structure of partner selection for a liner shipping company with seven criteria, thirty-two sub-criteria, and three alternatives was constructed to perform the empirical survey via AHP expert questionnaires. When the operations of fuzzy AHP algorithm are computed, the optimal alternative is selected as the partner for the liner shipping company.
\end{abstract}

\section{INTRODUCTION}

Strategic alliances between liner shipping companies have progressively displaced the traditional Shipping Conferences or Freight Conferences as the competitive form for liner carriers. Beginning in 1994, massive alignments between liner shipping carriers, and related shipping operators, took place with American President Line (APL), Orient Overseas Container Line (OOCL), Mitsui O.S.K. Line (MOL), and Nedlloyd Line forming the so-called "Global Alliance" [9] or the "First Generation Strategic Alliance" [13]. With limited resources, the formation of strategic alliances will enable individual carriers to share risks and resources, exchange knowledge, and access new markets $[6,15]$.

Based upon the strategic demand to maintain, or to increase, the competitive advantage, some liner shipping companies joined forces with one or more than two carriers on the collective relationships provided by contracts. Midoro and Pitto

Paper submitted 12/12/07; accepted 03/26/08. Author for correspondence: Ji-Feng Ding (e-mail: jfding@mail.cjcu.edu.tw).

*Department of Aviation and Maritime Transportation Management, Chang Jung Christian University, Gui-Ren, Tainan County 711, Taiwan, R.O.C.
[13] pointed out that the most important factors in the advent of strategic alliances in liner shipping include the need for wider geographical scope, the possibility of vessel planning and co-ordination on a global scale, risk and investment sharing, economies of scale, entry into new markets, increasing frequency of services, combining purchasing power and volume, etc.

In any partnerships, there are always inherent risks and potential structural and cultural incompatibilities. To ensure success, it is crucial that the partners, harboring different objectives and expectations, have a clear understanding of each other's similarities and differences and, at the same time, recognize the opportunities for mutual benefits under cooperative arrangements. Since partner selection is crucial, it is imperative for decision-makers to devise and recognize effective partner selection criteria as well as evaluate questions of compatibility and feasibility prior to the formation of any alliance.

The decision for partner selection poses a multi-criteria problem. There are situations in which information is incomplete, or imprecise, or views that are subjective, or endowed with linguistic characteristics, that collectively create a fuzzy decision-making environment. The extent analysis method of fuzziness-based analytic hierarchy process (AHP) approach, proposed by Chang [3] in 1996, is designed to minimize such adverse conditions and strengthen the choice process.

The aim of this paper is to apply the modified extent analysis method of fuzzy AHP approach to improve the quality of decision-making in selecting a suitable partner. The following section presents the research methodology. The modified extent analysis method of fuzzy AHP approach is proposed in Section II. A survey of selecting a partner is empirically studied in Section III. Conclusions are drawn in the last section.

\section{RESEARCH METHODOLOGY}

In this section, some of the concepts used in this paper are briefly introduced. These include the fuzzy set theory and extent analysis method of fuzzy AHP. 


\section{Fuzzy Set Theory}

The fuzzy set theory [20] is designed to deal with the extraction of the primary possible outcome from a multiplicity of information that is expressed in vague and imprecise terms. Fuzzy set theory treats vague data as possibility distributions in terms of set memberships. Once determined and defined, the sets of memberships in possibility distributions can be effectively used in logical reasoning. Triangular fuzzy numbers and the algebraic operations of fuzzy numbers are two major components of this section.

\section{1) Triangular Fuzzy Numbers}

In a universe of discourse $X$, a fuzzy subset $A$ of $X$ is defined by a membership function $f_{A}(x)$, which maps each element $x$ in $X$ to a real number in the interval $[0,1]$. The function value $f_{A}(x)$ represents the grade of membership of $x$ in $A$.

A fuzzy number $A$ [7] in real line $\Re$ is a triangular fuzzy number if its membership function $f_{A}: \Re \rightarrow[0,1]$ is

$$
f_{A}(x)= \begin{cases}(x-c) /(a-c), & c \leq x \leq a \\ (x-b) /(a-b), & a \leq x \leq b \\ 0, & \text { otherwise }\end{cases}
$$

with $-\infty<c \leq a \leq b<\infty$. The triangular fuzzy number can be denoted by $(c, a, b)$.

The parameter ' $a$ ' gives the maximal grade of $f_{A}(x)$, i.e., $f_{A}(a)=1$; it is the most probable value of the evaluation data. In addition, ' $c$ ' and ' $b$ ' are the lower and upper bounds of the available area for the evaluation data. They are used to reflect the fuzziness of the evaluation data. The narrower the interval $[c, b]$, the lower the fuzziness of the evaluation data.

The triangular fuzzy numbers are easy to use and easy to interpret. For example, 'a value approximately equal to 300 ' can be represented by $(295,300,306)$; and it can be represented with more leeway by $(290,300,313)$. In addition, the non-fuzzy number, an exact number, ' $a$ ' can be represented by $(a, a, a)$. For example, 'a value of 300' can be represented by $(300,300,300)$.

\section{2) The Algebraic Operations of Fuzzy Numbers}

In 1985, Chen proposed the Function Principle [4], which could be used as the fuzzy arithmetical operations between fuzzy numbers. The merit of the Function Principle not only does not change the type of membership function of fuzzy number after operations, but also can reduce the troublesomeness and tediousness of operations. In here, the Chen's Function Principle is used in this paper. Let $A_{1}=\left(c_{1}, a_{1}, b_{1}\right)$ and $A_{2}=\left(c_{2}, a_{2}, b_{2}\right)$ be fuzzy numbers. The algebraic operations of any two fuzzy numbers $A_{1}$ and $A_{2}$ can be expressed as - Fuzzy addition, $\oplus$ :

$$
A_{1} \oplus A_{2}=\left(c_{1}+c_{2}, a_{1}+a_{2}, b_{1}+b_{2}\right),
$$

where $c_{1}, a_{1}, b_{1}, c_{2}, a_{2}$, and $b_{2}$ are any real numbers.

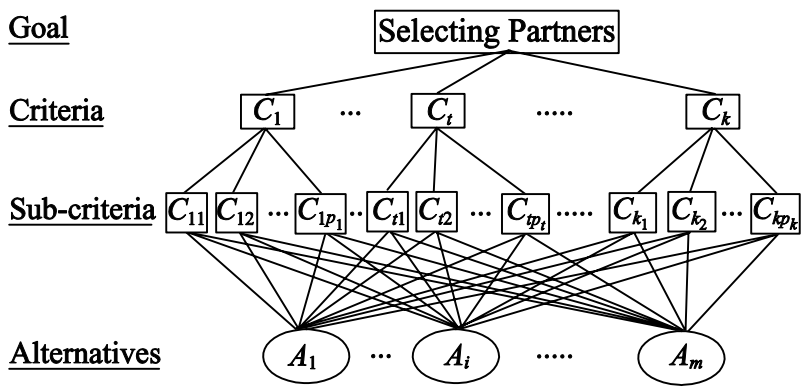

Fig. 1. Hierarchical structure.

- Fuzzy multiplication, $\otimes$ :

$$
A_{1} \otimes A_{2}=\left(c_{1} c_{2}, a_{1} a_{2}, b_{1} b_{2}\right),
$$

where $c_{1}, a_{1}, b_{1}, c_{2}, a_{2}$, and $b_{2}$ are all nonzero positive real numbers.

- Fuzzy division, $\varnothing$ :

$$
\left(A_{1}\right)^{-1}=\left(c_{1}, a_{1}, b_{1}\right)^{-1}=\left(1 / b_{1}, 1 / a_{1}, 1 / c_{1}\right),
$$

where $c_{1}, a_{1}$, and $b_{1}$ are all positive real numbers or all negative real numbers.

$$
A_{1} \varnothing A_{2}=\left(c_{1} / b_{2}, a_{1} / a_{2}, b_{1} / c_{2}\right),
$$

where $c_{1}, a_{1}, b_{1}, c_{2}, a_{2}$, and $b_{2}$ are all nonzero positive real numbers.

\section{The Modified Extent Analysis Method of Fuzzy AHP}

The systematic steps for selecting a partner using the extent analysis method of fuzzy AHP, which is modified Chang's method [3], is described below.

\section{Step 1: Develop a Hierarchical Structure}

A hierarchy structure is the framework of system structure. We can skeletonize a hierarchy to evaluate research problems and benefit the context. It is not only useful in studying the interaction amongst the elements involved in each level, but it can also help decision-makers to explore the impact of different elements on the evaluated system. Figure 1 is a complete hierarchical structure of selecting partners of strategic alliances with $k$ criteria, $p_{1}+\cdots+p_{t}+\cdots+p_{k}$ sub-criteria and $m$ alternatives.

\section{Step 2: Build Fuzzy Pair-wise Comparison Matrices}

Collecting pair-wise comparison matrices of each layer to represent the relative importance is an important step in fuzzy AHP method. Consequently, the relative importance are evaluated by experts and are transformed into triangular fuzzy numbers using the geometric mean approach [16] to convey the opinions of all experts. However, Chang's method used an arithmetic mean approach to obtain the relative importance. In this paper, the geometric mean approach is used instead of the arithmetic mean approach because the geometric mean is more effective in representing multiple decision-makers' consensus opinions [16]. 
Remark: The generalized means is a typical representation of many well-known averaging operations [11], e.g., min, max, geometric mean, arithmetic mean, harmonic mean, etc. The min and max are the lower bound and upper bound of generalized means, respectively. Besides, the geometric mean is more effective in representing the multiple decision-makers' consensus opinions [16]. To aggregate all information generated by different averaging operations, the author uses the grade of membership to demonstrate their strength after considering all approaches. For the above- mentioned reasons, the triangular fuzzy numbers characterized by using the min, max and geometric mean operations is used to convey the opinions of all decision-makers.

That is, let $x_{i j}^{h} \in[1 / 9,1] \cup[1,9], h=1,2, \ldots, n, \forall i, j=1$, $2, \ldots, k$, be the relative importance given to criteria $i$ to criteria $j$ by expert $h$ on the Criteria layer in Fig. 1. Then, the pair-wise comparison matrix is defined as $\left[x_{i j}^{h}\right]_{k \times k}$. After integrating the opinions of all $n$ experts, the triangular fuzzy numbers can be denoted by $\widetilde{B}_{i j}^{C}=\left(c_{i j}, a_{i j}, b_{i j}\right)$, where

$$
\begin{aligned}
& c_{i j}=\min \left\{x_{i j}^{1}, x_{i j}^{2}, \ldots, x_{i j}^{n}\right\}, a_{i j}=\left(\prod_{h=1}^{n} x_{i j}^{h}\right)^{1 / n}, \\
& b_{i j}=\max \left\{x_{i j}^{1}, x_{i j}^{2}, \ldots, x_{i j}^{n}\right\} .
\end{aligned}
$$

We use the integrated triangular fuzzy numbers to build a fuzzy pair-wise comparison matrix (given to criteria $i$ to criteria $j$ ). For the Criteria layer, the fuzzy pair-wise comparison matrix can be denoted by

$$
B_{k}^{C}=\left[\tilde{B}_{i j}^{C}\right]_{k \times k}=\left[\begin{array}{cccc}
1 & \tilde{B}_{12}^{C} & \cdots & \tilde{B}_{1 k}^{C} \\
1 / \tilde{B}_{12}^{C} & 1 & \cdots & \tilde{B}_{2 k}^{C} \\
\vdots & \vdots & \ddots & \vdots \\
1 / \tilde{B}_{1 k}^{C} & 1 / \tilde{B}_{2 k}^{C} & \cdots & 1
\end{array}\right],
$$

where $\tilde{B}_{i j}^{C} \otimes \tilde{B}_{j i}^{C}=1, \quad \forall i, j=1,2, \ldots, k$.

By the same concept, let $x_{u v}^{s h} \in[1 / 9,1] \cup[1,9], h=1,2, \ldots$, $n, \forall u, v=1, \ldots, p_{1} ; \forall u, v=1, \ldots, p_{t} ; \ldots ; \forall u, v=1, \ldots, p_{k}$, be the relative importance given to sub-criteria $u$ to sub-criteria $v$ by expert $h$ on the Sub-criteria layer in Fig. 1. Then, the pair-wise comparison matrices are defined as $\left[x_{u v}^{s h}\right]_{p_{1} \times p_{1}}, \cdots$, $\left[x_{u v}^{s h}\right]_{p_{t} \times p_{t}}, \ldots,\left[x_{u v}^{s h}\right]_{p_{k} \times p_{k}}$. Therefore, we can integrate the opinions of all $n$ experts given to sub-criteria $u$ to sub-criteria $v$ on the Sub-criteria layer, the triangular fuzzy numbers can be denoted by $\widetilde{B}_{u v}^{S C}=\left(c_{u v}, a_{u v}, b_{u v}\right), \forall u, v=1, \ldots, p_{1}, \forall u, v=1, \ldots$, $p_{t}, \ldots, \forall u, v=1, \ldots, p_{k}$, where

$c_{u v}=\min \left\{x_{u v}^{s 1}, x_{u v}^{s 2}, \ldots, x_{u v}^{s n}\right\}, a_{u v}=\left(\prod_{h=1}^{n} x_{u v}^{s h}\right)^{1 / n}$,

$b_{u v}=\max \left\{x_{u v}^{s 1}, x_{u v}^{s 2}, \ldots, x_{u v}^{s n}\right\}$.

We use the integrated triangular fuzzy numbers to build the fuzzy pair-wise comparison matrices for the Sub-criteria layer can be denoted by

$$
B_{p_{1}}^{S C}=\left[\tilde{B}_{u v}^{S C}\right]_{p_{1} \times p_{1}}=\left[\begin{array}{cccc}
1 & \tilde{B}_{12}^{S C} & \cdots & \tilde{B}_{1 p_{1}}^{S C} \\
1 / \tilde{B}_{12}^{S C} & 1 & \cdots & \tilde{B}_{2 p_{1}}^{S C} \\
\vdots & \vdots & \ddots & \vdots \\
1 / \tilde{B}_{1 p_{1}}^{S C} & 1 / \tilde{B}_{2 p_{1}}^{S C} & \cdots & 1
\end{array}\right]
$$

where $\tilde{B}_{u v}^{S C} \otimes \tilde{B}_{v u}^{S C}=1, \quad \forall u, v=1,2, \ldots, p_{1}$.

$$
B_{p_{t}}^{S C}=\left[\tilde{B}_{u v}^{S C}\right]_{p_{t} \times p_{t}}=\left[\begin{array}{cccc}
1 & \tilde{B}_{12}^{S C} & \cdots & \tilde{B}_{1 p_{t}}^{S C} \\
1 / \tilde{B}_{12}^{S C} & 1 & \cdots & \tilde{B}_{2 p_{t}}^{S C} \\
\vdots & \vdots & \ddots & \vdots \\
1 / \tilde{B}_{1 p_{t}}^{S C} & 1 / \tilde{B}_{2 p_{t}}^{S C} & \cdots & 1
\end{array}\right],
$$

where $\tilde{B}_{u v}^{S C} \otimes \widetilde{B}_{v u}^{S C}=1, \quad \forall u, v=1,2, \ldots, p_{t}$. and

$$
B_{p_{k}}^{S C}=\left[\tilde{B}_{u v}^{S C}\right]_{p_{k} \times p_{k}}=\left[\begin{array}{cccc}
1 & \tilde{B}_{12}^{S C} & \cdots & \tilde{B}_{1 p_{k}}^{S C} \\
1 / \tilde{B}_{12}^{S C} & 1 & \cdots & \tilde{B}_{2 p_{k}}^{S C} \\
\vdots & \vdots & \ddots & \vdots \\
1 / \tilde{B}_{1 p_{k}}^{S C} & 1 / \tilde{B}_{2 p_{k}}^{S C} & \cdots & 1
\end{array}\right]
$$

where $\tilde{B}_{u v}^{S C} \otimes \tilde{B}_{v u}^{S C}=1, \quad \forall u, v=1,2, \ldots, p_{k}$.

As regards with collecting pair-wise comparison matrices of $m$ alternatives versus all $p_{1}+\cdots+p_{t}+\cdots+p_{k}$ sub-criteria, let $x_{y z}^{a h} \in[1 / 9,1] \cup[1,9], h=1,2, \ldots, n, \forall y, z=1, \ldots, m$, be the relative importance given to alternative y to alternative $z$ versus all sub-criteria $\left(C_{11}, \ldots, C_{1 p_{1}}, \ldots \ldots, C_{t 1}, \ldots, C_{t p_{t}}, \ldots \ldots\right.$, $\left.C_{k 1}, \ldots, C_{k p_{k}}\right)$ by expert $h$ in Fig. 1 . Hence, there are $p_{1}+\ldots+$ $p_{t}+\ldots+p_{k}$ pair-wise comparison matrices and these matrices can be defined as $\left[x_{y z}^{a h}\right]_{m \times m}$. Therefore, the triangular fuzzy numbers of integrating all $n$ experts' opinions that given to alternative $y$ to alternative $z$ versus all sub-criteria $\left(C_{11}, \ldots\right.$, $C_{\sim_{1}}, \ldots . ., C_{t 1}, \ldots, C_{t p_{t}}, \ldots \ldots, C_{k 1}, \ldots, C_{k p_{k}}$ ) can be denoted by $\tilde{B}_{y z}^{A}=\left(c_{y z}, a_{y z}, b_{y z}\right), \forall y, z=1, \ldots, m$, where

$c_{y z}=\min \left\{x_{y z}^{a 1}, x_{y z}^{a 2}, \ldots, x_{y z}^{a n}\right\}, a_{y z}=\left(\prod_{h=1}^{n} x_{y z}^{a h}\right)^{1 / n}$,
$b_{y z}=\max \left\{x_{y z}^{a 1}, x_{y z}^{a 2}, \ldots, x_{y z}^{a n}\right\}$.

Then, we use the integrated triangular fuzzy numbers to build $p_{1}+\cdots+p_{t}+\cdots+p_{k}$ fuzzy pair-wise comparison matrices for the Alternatives layer versus all sub-criteria, and this can be denoted by

$B_{m}^{A}=\left[\tilde{B}_{y z}^{A}\right]_{m \times m}=\left[\begin{array}{cccc}1 & \tilde{B}_{12}^{A} & \cdots & \tilde{B}_{1 m}^{A} \\ 1 / \widetilde{B}_{12}^{A} & 1 & \cdots & \tilde{B}_{2 m}^{A} \\ \vdots & \vdots & \ddots & \vdots \\ 1 / \tilde{B}_{1 m}^{A} & 1 / \tilde{B}_{2 m}^{A} & \cdots & 1\end{array}\right]$,

where $\tilde{B}_{y z}^{A} \otimes \tilde{B}_{z y}^{A}=1, \quad \forall y, z=1,2, \ldots, m$. 


\section{Step 3: Calculate the Value of Fuzzy Synthetic Extent}

An important step of Chang's extent analysis method on fuzzy AHP is to define the value of the fuzzy synthetic extent. Let $X=\left\{x_{1}, x_{2}, \ldots, x_{n}\right\}$ be an object set, and $U=\left\{u_{1}, u_{2}, \ldots\right.$, $u_{m}$ \} be a goal set. According to Chang's extent analysis method, each object is taken, and an extent analysis for each goal, $g_{i}$, is performed, respectively. The $m$ extent analysis values for each object can be denoted as

$$
M_{g_{i}}^{1}, M_{g_{i}}^{2}, \cdots, M_{g_{i}}^{m}, \quad i=1,2, \ldots, n,
$$

where all the $M_{g_{i}}^{j}=\left(c_{j}, a_{j}, b_{j}\right), j=1,2, \ldots, m$, are triangular fuzzy numbers.

Let $M_{g_{i}}^{1}, M_{g_{i}}^{2}, \cdots, M_{g_{i}}^{m}$ be the values of extent analysis of $i^{\text {th }}$ object for $m$ goals. Then, the value of fuzzy synthetic extent with respect to the $i^{\text {th }}$ object is defined as

$$
S_{i}=\sum_{j=1}^{m} M_{g_{i}}^{j} \otimes\left[\sum_{i=1}^{n} \sum_{j=1}^{m} M_{g_{i}}^{j}\right]^{-1},
$$

where $\sum_{j=1}^{m} M_{g_{i}}^{j}=\left(\sum_{j=1}^{m} c_{j}, \sum_{j=1}^{m} a_{j}, \sum_{j=1}^{m} b_{j}\right)=\left(L_{i}, M_{i}, U_{i}\right)$,

$$
\sum_{i=1}^{n} \sum_{j=1}^{m} M_{g_{i}}^{j}=\left(\sum_{i=1}^{n} L_{i}, \sum_{i=1}^{n} M_{i}, \sum_{i=1}^{n} U_{i}\right), \text { and }
$$

$$
\left[\sum_{i=1}^{n} \sum_{j=1}^{m} M_{g_{i}}^{j}\right]^{-1}=\left(\frac{1}{\sum_{i=1}^{n} U_{i}}, \frac{1}{\sum_{i=1}^{n} M_{i}}, \frac{1}{\sum_{i=1}^{n} L_{i}}\right) .
$$

To easily interpret each layer, now we take the Criteria layer in Fig. 1 as the subject matter. The fuzzy pair-wise comparison matrix on the Criteria layer is denoted by

$$
B_{k}^{C}=\left[\tilde{B}_{i j}^{C}\right]_{k \times k}=\left[\begin{array}{cccc}
1 & \tilde{B}_{12}^{C} & \cdots & \tilde{B}_{1 k}^{C} \\
1 / \tilde{B}_{12}^{C} & 1 & \cdots & \tilde{B}_{2 k}^{C} \\
\vdots & \vdots & \ddots & \vdots \\
1 / \tilde{B}_{1 k}^{C} & 1 / \tilde{B}_{2 k}^{C} & \cdots & 1
\end{array}\right], \quad \forall i, j=1,2, \ldots, k .
$$

By using (2), the value of fuzzy synthetic extent with respect to the $C_{1}$ can be obtained and denoted by

$$
\begin{aligned}
& S_{1}=\sum_{t=1}^{k} \tilde{B}_{1 t}^{C} \otimes\left[\sum_{s=1}^{k} \sum_{t=1}^{k} \tilde{B}_{s t}^{C}\right]^{-1}, \\
& \text { where } \sum_{t=1}^{k} \tilde{B}_{1 t}^{C}=\left(\sum_{t=1}^{k} c_{1 t}, \sum_{t=1}^{k} a_{1 t}, \sum_{t=1}^{k} b_{1 t}\right) \text { and } \\
& {\left[\sum_{s=1}^{k} \sum_{t=1}^{k} \tilde{B}_{t t}^{C}\right]^{-1}=\left(1 / \sum_{s=1}^{k} \sum_{t=1}^{k} b_{s t}, 1 / \sum_{s=1}^{k} \sum_{t=1}^{k} a_{s t}, 1 / \sum_{s=1}^{k} \sum_{t=1}^{k} c_{s t}\right) .}
\end{aligned}
$$

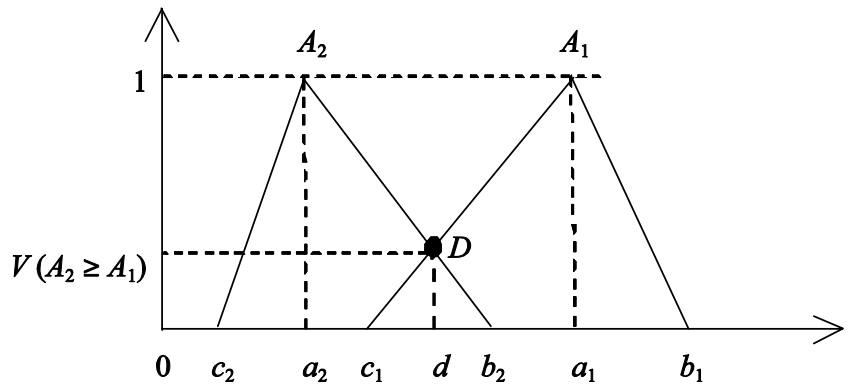

Fig. 2. The intersection point of $D$ between $f_{A_{1}}$ and $f_{A_{2}}$.

To save space, the value of fuzzy synthetic extent with respect to the $C_{t}(t=1,2, \ldots, k)$ can be obtained by the same concept as for the Criteria layer. The equations of value of fuzzy synthetic extent with respect to the Sub-criteria layer and Alternatives layer versus all sub-criteria are omitted to reason by analogy.

\section{Step 4: Compare the Degree of Possibility Among Fuzzy Synthetic Extent Value}

Calculating the degree of possibility of any two fuzzy numbers is another important step in Chang's method. This step can obtain to compare which is the greatest fuzzy value among several fuzzy numbers.

Let $A_{1}=\left(c_{1}, a_{1}, b_{1}\right)$ and $A_{2}=\left(c_{2}, a_{2}, b_{2}\right)$ be fuzzy numbers, then the degree of possibility of $A_{2} \geq A_{1}$ is defined as $V\left(A_{2} \geq A_{1}\right)=\sup _{y \geq x}\left[\min \left(f_{A_{1}}(x), f_{A_{2}}(y)\right)\right]$. The degree of possibility of $A_{2} \geq A_{1}$ can be also expressed as

$$
\begin{aligned}
V\left(A_{2} \geq A_{1}\right)= & h g t\left(A_{1} \cap A_{2}\right)=f_{A_{2}}(d) \\
& = \begin{cases}1, & \text { if } a_{2} \geq a_{1} \\
0, & \text { if } c_{1} \geq b_{2} \\
\frac{c_{1}-b_{2}}{\left(a_{2}-b_{2}\right)-\left(a_{1}-c_{1}\right)}, & \text { otherwise }\end{cases}
\end{aligned}
$$

where $d$ is the ordinate of the highest intersection point of $D$ between $f_{A_{1}}$ and $f_{A_{2}}$ (see Fig. 2). In order to compare $A_{1}$ and $A_{2}$, we need both the values of $V\left(A_{1} \geq A_{2}\right)$ and $V\left(A_{2} \geq A_{1}\right)$.

The degree of possibility for a convex fuzzy number $A$ to be greater than $k$ convex fuzzy numbers $A_{i}(i=1,2, \ldots, k)$ can be defined by

$$
\begin{aligned}
V(A & \left.\geq A_{1}, A_{2}, \ldots, A_{k}\right) \\
& =V\left[\left(A \geq A_{1}\right) \text { and }\left(A \geq A_{2}\right) \text { and } \ldots \text { and }\left(A \geq A_{k}\right)\right] \\
& =\min \left\{V\left(A \geq A_{i}\right), \quad i=1,2, \ldots, k\right\} .
\end{aligned}
$$

\section{Step 5: Calculate and Normalize the Weight Vector of Each Layer}

After collecting the pair-wise comparison matrices of each layer, the value of the fuzzy synthetic extent and the degree of possibility of $k$ convex fuzzy numbers can be calculated from Chang's method. The next step is using this information to 
obtain the weight vector of each layer. To easily interpret for each layer, now we take the Criteria layer in Fig. 1 as the subject matter.

Assume that $d^{\prime}\left(C_{t}\right)=\min \left\{V\left(S_{t} \geq S_{p}\right)\right.$, for $p=1,2, \ldots, k$; $p \neq t$. Then, the weight vector of the Criteria layer is given by $W^{\prime}=\left(d^{\prime}\left(C_{1}\right), d^{\prime}\left(C_{2}\right), \ldots, d^{\prime}\left(C_{t}\right)\right)^{T}$, where $C_{t}(t=1,2, \ldots$, $k)$ are $k$ criteria.

For being convenient to obtain the relative importance of each layer, the normalized weight vector is $W=\left(d\left(C_{1}\right)\right.$, $\left.d\left(C_{2}\right), \ldots ., d\left(C_{t}\right)\right)^{T}$, where $W$ is a non-fuzzy number. Here, the normalized weights can be also expressed as

$$
d\left(C_{t}\right)=\frac{d^{\prime}\left(C_{t}\right)}{\sum_{t=1}^{k} d^{\prime}\left(C_{t}\right)}, t=1,2, \ldots, k
$$

To save space, the weight vector of Sub-criteria layer and Alternatives layer versus all sub-criteria can be obtained by the same concept.

\section{Step 6: Choose the Optimal Alternative}

Let $W_{t}, W_{t j}$, and $W_{t j}^{i}, t=1,2, \ldots, k, j=1,2, \ldots, p_{1}, j=1$, $2, \ldots, p_{t}, \ldots, j=1,2, \ldots, p_{k}, i=1,2, \ldots, m$, be the normalized weights of the Criteria layer, be the normalized weights of the Sub-criteria layer, and be the normalized weights of Alternatives layer versus all sub-criteria, respectively. Then, the final integrated weights for each alternative can be denoted by $F I W_{i}=W_{t} \times W_{t j} \times W_{t j}^{i}$. Finally, based on these final integrated weights, the decision-maker can determine the optimal alternative.

\section{EMPIRICAL STUDY}

In this section, an empirical study of selecting a partner of strategic alliance for a liner shipping company is utilized to demonstrate the computational process of this modified fuzzy AHP as described above. The process of the algorithm is empirically implemented, step by step, as follows.

\section{Identify the Alternatives and Adopt the Selection Criteria}

In a multi-criteria evaluation problem, the prospective alternatives and numerous selection criteria needed to be considered. The following paragraphs record the hierarchical structure of partner selection for a liner shipping company with seven criteria, thirty-two sub-criteria and three alternatives. These can be constructed as in Fig. 1.

In our case, a container shipping company needs to choose a partner to expand business. Three candidate companies, named A Line $(A L)$, B Line $(B L)$, and $\mathrm{C}$ Line $(C L)$, are chosen after a preliminary screening for further evaluation. The criteria and sub-criteria used for the partner selection are derived from the related literature [1, 2, 5, 6, 8-10, 12, 13, 15, 17-19], suggestions of management, government officials and academic professors. Finally, seven criteria and thirty-two sub-criteria are suggested and the code names of these criteria and sub-criteria are shown in parentheses.

- Complementary capabilities $\left(C_{1}\right)$. This criterion includes six sub-criteria, that is, wider and deeper geographical scope $\left(C_{11}\right)$, managerial capabilities of lines $\left(C_{12}\right)$, service channels or places $\left(C_{13}\right)$, increase in frequency of service $\left(C_{14}\right)$, net handling performance at container terminal $\left(C_{15}\right)$, and increase in local or regional market access $\left(C_{16}\right)$.

- Deeper contents and forms of collaboration $\left(C_{2}\right)$. This criterion includes five sub-criteria, that is, ships fitting with the cooperative routes $\left(C_{21}\right)$, using dedicated terminals together $\left(C_{22}\right)$, extending interests in the integrated hinterland transport service $\left(C_{23}\right)$, business-supported activities $\left(C_{24}\right)$, and co-ordination of sales and marketing activities $\left(C_{25}\right)$.

- Similarities match with partners $\left(C_{3}\right)$. This criterion includes six sub-criteria, that is, cultures $\left(C_{31}\right)$, communication and coordination $\left(C_{32}\right)$, symmetry in organizational size $\left(C_{33}\right)$, trust and commitment $\left(C_{34}\right)$, compatibility in strategic goals $\left(C_{35}\right)$, and conflict management techniques $\left(C_{36}\right)$.

- Financial health $\left(C_{4}\right)$. This criterion includes four sub-criteria, that is, return on stockholders' equity $\left(C_{41}\right)$, profit margin $\left(C_{42}\right)$, return on assets $\left(C_{43}\right)$, and return on long-term investment $\left(C_{44}\right)$.

- Adequate physical facilities and equipment $\left(C_{5}\right)$. This criterion includes four sub-criteria, that is, handling equipment $\left(C_{51}\right)$, terminal hectares $\left(C_{52}\right)$, using containers and chassis together $\left(C_{53}\right)$, and information-sharing system $\left(C_{54}\right)$.

- Intangible assets $\left(C_{6}\right)$. This criterion includes three sub-criteria, that is, brand and firm reputation $\left(C_{61}\right)$, experience sharing $\left(C_{62}\right)$, and good human resources $\left(C_{63}\right)$.

- Market knowledge access $\left(C_{7}\right)$. This criterion includes four sub-criteria, that is, understanding competitors and customers $\left(C_{71}\right)$, experience with government regulations $\left(C_{72}\right)$, unique competencies $\left(C_{73}\right)$, and capabilities to provide total quality service $\left(C_{74}\right)$.

\section{Questionnaire Design and Data Collect}

Seven criteria, thirty-two sub-criteria with three alternatives were used to design the Saaty's [16] AHP questionnaire, and to collect pair-wise comparison matrices of each layer to represent the relative importance. The AHP problem is involved with the group decision-making, where Robbins [14] suggested five or seven decision-makers are suitable for dealing with a group decision-making problem. For this research, a committee of seven senior directors and managers in a company had been engaged to answer the survey questionnaire. The surveys were completed in 2007 through e-mails, phone calls, and in-person interviews conducted by the author. All of the seven questionnaires were checked for validity.

\section{Empirical Results}

In our case, with seven criteria, thirty-two sub-criteria with three alternatives, there are forty $(1+7+32)$ pair-wise com- 
Table 1. The fuzzy pair-wise comparison matrix of seven criteria.

\begin{tabular}{|c|c|c|c|c|c|c|c|}
\hline & $C_{1}$ & $C_{2}$ & $C_{3}$ & $C_{4}$ & $C_{5}$ & $C_{6}$ & $C_{7}$ \\
\hline$C_{1}$ & $(1,1,1)$ & $(0.2,1.640,5)$ & $(2,4.820,9)$ & $(0.333,2.370,7)$ & $(0.5,2.135,6)$ & $(1,3.717,7)$ & $(2,4.787,8)$ \\
\hline$C_{2}$ & $(0.2,0.609,5)$ & $(1,1,1)$ & $(1,4.494,9)$ & $(0.2,1.952,5)$ & $(0.167,1.060,5)$ & $(0.167,2.411,9)$ & $(0.167,2.827,9)$ \\
\hline$C_{3}$ & $(0.111,0.207,0.5)$ & $(0.111,0.223,1)$ & $(1,1,1)$ & $(0.167,0.319,3)$ & $(0.2,0.399,2)$ & $(0.143,0.704,3)$ & $(0.143,0.895,4)$ \\
\hline$C_{4}$ & $(0.143,0.422,3)$ & $(0.2,0.464,5)$ & $(0.333,3.138,6)$ & $(1,1,1)$ & $(0.2,0.548,2)$ & $(0.167,1.121,6)$ & $(0.167,1.341,7)$ \\
\hline$C_{5}$ & $(0.167,0.468,2)$ & $(0.2,0.943,6)$ & $(0.5,2.508,5)$ & $(0.5,1.825,5)$ & $(1,1,1)$ & $(0.333,2.283,6)$ & $(0.333,2.860,7)$ \\
\hline$C_{6}$ & $(0.143,0.269,1)$ & $(0.111,0.415,6)$ & $(0.333,1.420,7)$ & $(0.167,0.892,6)$ & $(0.167,0.438,3)$ & $(1,1,1)$ & $(1,2.034,3)$ \\
\hline$C_{7}$ & $(0.125,0.209,0.5)$ & $(0.111,0.354,6)$ & $(0.25,1.118,7)$ & $(0.143,0.746,6)$ & $(0.143,0.350,3)$ & $(0.333,0.492,1)$ & $(1,1,1)$ \\
\hline
\end{tabular}

parison matrices to collect. The author uses the seven criteria $\left(C_{1}-C_{7}\right)$ of the seven valid questionnaires as an example for illustrating the computational process of the modified fuzzy AHP. As regards to the 39 pair-wise comparison matrices, these are omitted by reasoning by analogy. Then, the weight vectors and normalized weights for the Criteria layer are calculated. Finally, the computing process and empirical results are shown as follows.

\section{Step 1: Build Fuzzy Pair-wise Comparison Matrix}

The author used the data of the relative importance of seven valid questionnaires to collect pair-wise comparison matrix and then transformed these data into triangular fuzzy numbers using the geometric mean approach, as mentioned in Step 2 of modified extent analysis method of fuzzy AHP. The result of the fuzzy pair-wise comparison matrix $\left(B_{k}^{C}=\left[\tilde{B}_{i j}^{C}\right\rfloor_{7 \times 7}\right)$ for the Criteria layer $\left(C_{1}-C_{7}\right)$ is shown as Table 1 .

\section{Step 2: Calculate the Value of Fuzzy Synthetic Extent}

Using the (2), the value of fuzzy synthetic extent with respect to the $C_{1}$ to $C_{7}$ can be obtained. The computational process is described below.

$$
\begin{aligned}
S_{1} & =(7.033,20.469,43) \otimes\left(\frac{1}{214}, \frac{1}{69.227}, \frac{1}{22.078}\right) \\
& =(0.033,0.296,1.948),
\end{aligned}
$$

$$
\begin{aligned}
S_{2} & =(2.901,14.353,43) \otimes\left(\frac{1}{214}, \frac{1}{69.227}, \frac{1}{22.078}\right) \\
& =(0.014,0.207,1.948),
\end{aligned}
$$

$$
\begin{aligned}
S_{3} & =(1.875,3.747,14.5) \otimes\left(\frac{1}{214}, \frac{1}{69.227}, \frac{1}{22.078}\right) \\
& =(0.009,0.054,0.657),
\end{aligned}
$$$$
\begin{aligned}
S_{4} & =(2.210,8.034,30) \otimes\left(\frac{1}{214}, \frac{1}{69.227}, \frac{1}{22.078}\right) \\
& =(0.010,0.116,1.359)
\end{aligned}
$$$$
S_{5}=(3.033,11.887,32) \otimes\left(\frac{1}{214}, \frac{1}{69.227}, \frac{1}{22.078}\right)
$$$$
=(0.014,0.172,1.449) \text {, }
$$

$$
\begin{aligned}
S_{6} & =(2.921,6.468,27) \otimes\left(\frac{1}{214}, \frac{1}{69.227}, \frac{1}{22.078}\right) \\
& =(0.014,0.093,1.223), \\
S_{7} & =(2.105,4.269,24.5) \otimes\left(\frac{1}{214}, \frac{1}{69.227}, \frac{1}{22.078}\right) \\
& =(0.010,0.062,1.110) .
\end{aligned}
$$

Step 3: Compare the Degree of Possibility Among Fuzzy Synthetic Extent Value

By using (3), the degree of possibility $\left(V\left(S_{i} \geq S_{j}\right)\right)$ among these seven fuzzy synthetic extent value $\left(S_{1}\right.$ to $\left.S_{7}\right)$ can be obtained. The computational process is described below.

(1) $V\left(S_{1} \geq S_{2}\right)=1 ; V\left(S_{1} \geq S_{3}\right)=1 ; V\left(S_{1} \geq S_{4}\right)=1$;

$$
V\left(S_{1} \geq S_{5}\right)=1 ; V\left(S_{1} \geq S_{6}\right)=1 ; V\left(S_{1} \geq S_{7}\right)=1 .
$$

(2) $V\left(S_{2} \geq S_{1}\right)=\frac{0.033-1.948}{(0.207-1.948)-(0.296-0.033)}=0.956$;

$$
\begin{aligned}
& V\left(S_{2} \geq S_{3}\right)=1 ; V\left(S_{2} \geq S_{4}\right)=1 ; V\left(S_{2} \geq S_{5}\right)=1 ; \\
& V\left(S_{2} \geq S_{6}\right)=1 ; V\left(S_{2} \geq S_{7}\right)=1 .
\end{aligned}
$$

(3) $V\left(S_{3} \geq S_{1}\right)=\frac{0.033-0.657}{(0.054-0.657)-(0.296-0.033)}=0.721$;

$$
\begin{aligned}
& V\left(S_{3} \geq S_{2}\right)=\frac{0.014-0.657}{(0.054-0.657)-(0.207-0.014)}=0.808 \\
& V\left(S_{3} \geq S_{4}\right)=\frac{0.01-0.657}{(0.054-0.657)-(0.116-0.01)}=0.913
\end{aligned}
$$$$
V\left(S_{3} \geq S_{5}\right)=\frac{0.014-0.657}{(0.054-0.657)-(0.172-0.014)}=0.845
$$$$
V\left(S_{3} \geq S_{6}\right)=\frac{0.014-0.657}{(0.054-0.657)-(0.093-0.014)}=0.943
$$

$$
V\left(S_{3} \geq S_{7}\right)=\frac{0.01-0.657}{(0.054-0.657)-(0.062-0.01)}=0.988 .
$$


(4) $V\left(S_{4} \geq S_{1}\right)=\frac{0.033-1.359}{(0.116-1.359)-(0.296-0.033)}=0.881$;

$V\left(S_{4} \geq S_{2}\right)=\frac{0.014-1.359}{(0.116-1.359)-(0.207-0.014)}=0.937 ;$

$V\left(S_{4} \geq S_{3}\right)=1$;

$V\left(S_{4} \geq S_{5}\right)=\frac{0.014-1.359}{(0.116-1.359)-(0.172-0.014)}=0.960 ;$

$V\left(S_{4} \geq S_{6}\right)=\frac{0.014-1.359}{(0.116-1.359)-(0.093-0.014)}=0.983$;

$V\left(S_{4} \geq S_{7}\right)=1$.

(5) $V\left(S_{5} \geq S_{1}\right)=\frac{0.033-1.449}{(0.172-1.449)-(0.296-0.033)}=0.919$;

$V\left(S_{5} \geq S_{2}\right)=\frac{0.014-1.449}{(0.172-1.449)-(0.207-0.014)}=0.976$;

$V\left(S_{5} \geq S_{3}\right)=1 ; V\left(S_{5} \geq S_{4}\right)=1 ; V\left(S_{5} \geq S_{6}\right)=1 ;$

$V\left(S_{5} \geq S_{7}\right)=1$.

(6) $V\left(S_{6} \geq S_{1}\right)=\frac{0.033-1.223}{(0.093-1.223)-(0.296-0.033)}=0.854$;

$V\left(S_{6} \geq S_{2}\right)=\frac{0.014-1.223}{(0.093-1.223)-(0.207-0.014)}=0.914 ;$

$V\left(S_{6} \geq S_{3}\right)=1$

$V\left(S_{6} \geq S_{4}\right)=\frac{0.01-1.223}{(0.093-1.223)-(0.116-0.01)}=0.981 ;$

$V\left(S_{6} \geq S_{5}\right)=\frac{0.014-1.223}{(0.093-1.223)-(0.172-0.014)}=0.939 ;$

$V\left(S_{6} \geq S_{7}\right)=1$

(7) $V\left(S_{7} \geq S_{1}\right)=\frac{0.033-1.11}{(0.062-1.11)-(0.296-0.033)}=0.822$;

$V\left(S_{7} \geq S_{2}\right)=\frac{0.014-1.11}{(0.062-1.11)-(0.207-0.014)}=0.883 ;$

$V\left(S_{7} \geq S_{3}\right)=1$

$V\left(S_{7} \geq S_{4}\right)=\frac{0.01-1.11}{(0.062-1.11)-(0.116-0.01)}=0.953 ;$
Table 2. The normalized weights of the seven criteria.

\begin{tabular}{|c|c|c|c|c|}
\hline Criteria & $C_{1}$ & $C_{2}$ & $C_{3}$ & $C_{4}$ \\
\hline Normalized weights & 0.163 & 0.155 & 0.117 & 0.143 \\
\cline { 1 - 4 } Criteria & $C_{5}$ & $C_{6}$ & $C_{7}$ & \multicolumn{1}{|}{} \\
\cline { 1 - 3 } Normalized weights & 0.149 & 0.139 & 0.134 & \multicolumn{1}{|c}{} \\
\cline { 1 - 3 } & &
\end{tabular}

$$
\begin{aligned}
& V\left(S_{7} \geq S_{5}\right)=\frac{0.014-1.11}{(0.062-1.11)-(0.172-0.014)}=0.909 ; \\
& V\left(S_{7} \geq S_{6}\right)=\frac{0.014-1.11}{(0.062-1.11)-(0.093-0.014)}=0.972 .
\end{aligned}
$$

\section{Step 4: Calculate and Normalize the Weight Vector}

Using the equation of $d^{\prime}\left(C_{t}\right)=\min \left\{V\left(S_{t} \geq S_{p}\right)\right\}$, the weight vector and normalized weight vector of the Criteria layer can be obtained. The computational process is described below.

$$
\begin{aligned}
d^{\prime}\left(C_{1}\right) & =\min \left\{V\left(S_{1} \geq S_{2}, S_{3}, S_{4}, S_{5}, S_{6}, S_{7}\right)\right\} \\
& =\min (1,1,1,1,1,1)=1 ; \\
d^{\prime}\left(C_{2}\right) & =\min \left\{V\left(S_{2} \geq S_{1}, S_{3}, S_{4}, S_{5}, S_{6}, S_{7}\right)\right\} \\
& =\min (0.956,1,1,1,1,1)=0.956 ; \\
d^{\prime}\left(C_{3}\right) & =\min \left\{V\left(S_{3} \geq S_{1}, S_{2}, S_{4}, S_{5}, S_{6}, S_{7}\right)\right\} \\
& =\min (0.721,0.808,0.913,0.845,0.943,0.988)=0.721 ; \\
d^{\prime}\left(C_{4}\right) & =\min \left\{V\left(S_{4} \geq S_{1}, S_{2}, S_{3}, S_{5}, S_{6}, S_{7}\right)\right\} \\
& =\min (0.881,0.937,1,0.960,0.983,1)=0.881 ; \\
d^{\prime}\left(C_{5}\right) & =\min \left\{V\left(S_{5} \geq S_{1}, S_{2}, S_{3}, S_{4}, S_{6}, S_{7}\right)\right\} \\
& =\min (0.919,0.976,1,1,1,1)=0.919 ; \\
d^{\prime}\left(C_{6}\right) & =\min \left\{V\left(S_{6} \geq S_{1}, S_{2}, S_{3}, S_{4}, S_{5}, S_{7}\right)\right\} \\
& =\min (0.854,0.914,1,0.981,0.939,1)=0.854 ; \\
d^{\prime}\left(C_{7}\right) & =\min \left\{V\left(S_{7} \geq S_{1}, S_{2}, S_{3}, S_{4}, S_{5}, S_{6}\right)\right\} \\
& =\min (0.822,0.883,1,0.953,0.909,0.972)=0.822 .
\end{aligned}
$$

The weight vector of the Criteria layer is calculated as $W^{\prime}=$ $(1,0.956,0.721,0.881,0.919,0.854,0.822)^{T}$, and the normalized weight vector is $W=(0.163,0.155,0.117,0.143$, $0.149,0.139,0.134)^{T}$.

Therefore, the weight of each criterion $\left(C_{1}-C_{7}\right)$ of the Criteria layer can be shown as Table 2 .

\section{Step 5: Calculate the Weights for Each Layer}

To save space, the author used the same computational process of the proposed fuzzy AHP for each layer to obtain the normalized weights. And then, the results of the normalized weights for each layer can be shown as Table 3 . 
Table 3. The normalized weights for each layer.

\begin{tabular}{|c|c|c|c|c|c|c|}
\hline \multirow{2}{*}{$\begin{array}{c}\text { Criteria } \\
\text { layer }\end{array}$} & \multirow[t]{2}{*}{ Weights } & \multirow{2}{*}{$\begin{array}{c}\text { Sub-criteria } \\
\text { layer }\end{array}$} & \multirow[t]{2}{*}{ Weights } & \multicolumn{3}{|c|}{$\begin{array}{l}\text { Alternatives layer versus } \\
\text { all sub-criteria (Weights) }\end{array}$} \\
\hline & & & & $A L$ & $B L$ & $C L$ \\
\hline \multirow{6}{*}{$C_{1}$} & \multirow{6}{*}{0.163} & $C_{11}$ & 0.261 & 0.255 & 0.226 & 0.519 \\
\hline & & $C_{12}$ & 0.109 & 0.261 & 0.432 & 0.307 \\
\hline & & $C_{13}$ & 0.175 & 0.269 & 0.397 & 0.334 \\
\hline & & $C_{14}$ & 0.189 & 0.226 & 0.391 & 0.383 \\
\hline & & $C_{15}$ & 0.127 & 0.289 & 0.238 & 0.473 \\
\hline & & $C_{16}$ & 0.139 & 0.452 & 0.299 & 0.249 \\
\hline \multirow{5}{*}{$C_{2}$} & \multirow{5}{*}{0.155} & $C_{21}$ & 0.293 & 0.351 & 0.334 & 0.315 \\
\hline & & $C_{22}$ & 0.186 & 0.229 & 0.412 & 0.359 \\
\hline & & $C_{23}$ & 0.243 & 0.301 & 0.287 & 0.412 \\
\hline & & $C_{24}$ & 0.159 & 0.279 & 0.258 & 0.463 \\
\hline & & $C_{25}$ & 0.119 & 0.259 & 0.358 & 0.383 \\
\hline \multirow{6}{*}{$C_{3}$} & \multirow{6}{*}{0.117} & $C_{31}$ & 0.121 & 0.286 & 0.295 & 0.419 \\
\hline & & $C_{32}$ & 0.193 & 0.324 & 0.298 & 0.396 \\
\hline & & $C_{33}$ & 0.181 & 0.298 & 0.283 & 0.419 \\
\hline & & $C_{34}$ & 0.208 & 0.357 & 0.314 & 0.329 \\
\hline & & $C_{35}$ & 0.159 & 0.389 & 0.253 & 0.358 \\
\hline & & $C_{36}$ & 0.138 & 0.298 & 0.251 & 0.451 \\
\hline \multirow{4}{*}{$C_{4}$} & \multirow{4}{*}{0.143} & $C_{41}$ & 0.223 & 0.228 & 0.283 & 0.489 \\
\hline & & $C_{42}$ & 0.403 & 0.297 & 0.387 & 0.316 \\
\hline & & $C_{43}$ & 0.215 & 0.353 & 0.226 & 0.421 \\
\hline & & $C_{44}$ & 0.159 & 0.236 & 0.312 & 0.452 \\
\hline \multirow{4}{*}{$C_{5}$} & \multirow{4}{*}{0.149} & $C_{51}$ & 0.263 & 0.319 & 0.383 & 0.298 \\
\hline & & $C_{52}$ & 0.241 & 0.296 & 0.345 & 0.359 \\
\hline & & $C_{53}$ & 0.318 & 0.326 & 0.248 & 0.426 \\
\hline & & $C_{54}$ & 0.178 & 0.382 & 0.245 & 0.373 \\
\hline \multirow{3}{*}{$C_{6}$} & \multirow{3}{*}{0.139} & $C_{61}$ & 0.381 & 0.389 & 0.218 & 0.393 \\
\hline & & $C_{62}$ & 0.256 & 0.294 & 0.287 & 0.426 \\
\hline & & $C_{63}$ & 0.363 & 0.391 & 0.235 & 0.374 \\
\hline \multirow{4}{*}{$C_{7}$} & \multirow{4}{*}{0.134} & $C_{71}$ & 0.224 & 0.378 & 0.276 & 0.346 \\
\hline & & $C_{72}$ & 0.216 & 0.248 & 0.384 & 0.368 \\
\hline & & $C_{73}$ & 0.257 & 0.297 & 0.278 & 0.425 \\
\hline & & $C_{74}$ & 0.303 & 0.374 & 0.231 & 0.395 \\
\hline
\end{tabular}

Table 4. The final integrated weights for three alternatives.

\begin{tabular}{|c|c|c|}
\hline Company & Final integrated weights $\left(F I W_{i}\right)$ & Ranking order \\
\hline$A L$ & 0.314 & 2 \\
\hline$B L$ & 0.299 & 3 \\
\hline$C L$ & 0.387 & 1 \\
\hline
\end{tabular}

\section{Step 6: Choose the Optimal Alternative}

Finally, the final integrated weights for each candidate $(A L$, $B L$, and $C L$ ) are obtained. The results are shown in Table 4. The ranking order of three alternatives is $C L, A L$, and $B L$. It is obvious that the optimal partner selection is alternative $C L$.

\section{CONCLUSIONS}

The strategic alliances amongst leading container carriers in the liner shipping industry have gained importance and prominence in recent years. The literature has shown that the formation of viable strategic alliances in the liner shipping industry has accelerated by necessity. However, the selection of a suitable partner for the strategic alliance is no easy matter. It not only involves a multiplicity of complex considerations but also concerns about data of vague information. This decision for partner selection poses a multi-criteria problem and endows with linguistic characteristics creating a fuzzy decision-making environment.

Hence, this paper aims to apply the modified extent analysis method of fuzzy AHP approach for selecting partners of strategic alliance for a liner shipping company. To find out the most appropriate company for selecting a partner based on the proposed fuzzy AHP algorithm, an empirical survey of a liner company was studied. To facilitate the main issue for selecting a partner, a hierarchical structure of partner selection for a liner shipping company with seven criteria, thirty-two sub-criteria and three alternatives was constructed. These criteria and sub-criteria have already been discussed and publicized in the academic and management fields. Finally, the proposed fuzzy AHP approach, which modifies Chang's method, was used to perform the empirical survey via an AHP expert questionnaire.

The surveys selected seven senior directors and managers to answer the survey questionnaires in 2007 . When the operations of fuzzy AHP algorithm are computed, alternative $C L$ was selected as the optimal partner for the liner shipping company. The proposed model does not only overcome the limitations of crisp values, but it also facilitates computerbased implementation as a decision support system for choice in fuzzy environments. In addition, the proposed algorithm can also be applied to similar selection problems, such as port selection, pilot selection, and so on.

\section{ACKNOWLEDGMENTS}

This paper is partially based upon the result of the research sponsored by National Science Council of the Republic of China, under the project number of NSC96-2416-H-309-004. The author would like to thank three anonymous referees for their excellent comments and valuable advice in this paper.

\section{REFERENCES}

1. Angels, R. and Nath, R., "An empirical of EDI trading partner selection criteria in customer-supplier relationships," Information and Management, Vol. 37, No. 5, pp. 241-255 (2000).

2. Beamish, P. W., "Joint ventures in LCD: partner selection and performance," Management International Review, Vol. 34, No. 1, pp. 60-74 (1994).

3. Chang, D. Y., "Application of the extent analysis method on fuzzy AHP," European Journal of Operational Research, Vol. 95, No. 3, pp. 649-655 (1996). 
4. Chen, S. H., "Operations on fuzzy numbers with function principle," Tamkang Journal of Management Sciences, Vol. 6, No. 1, pp. 13-26 (1985).

5. Cullinane, K. and Khanna, M., "Economies of scale in large containerships: optimal size and geographical implications," Journal of Transport Geography, Vol. 8, No. 3, pp. 181-195 (2000).

6. Dacin, M. T., Hitt, M. A., and Levitas, E., "Selecting partners for successful international alliances: examination of U.S. and Korean firms," Journal of World Business, Vol. 32, No. 1, pp. 3-16 (1997).

7. Dubois, D. and Prade, H., "Operations on fuzzy numbers," The International Journal of Systems Sciences, Vol. 9, No. 6, pp. 613-626 (1978).

8. Geringer, J. M., "Strategic determinants of partner selection criteria in international joint ventures," Journal of International Business Studies, Vol. 22, No. 1, pp. 41-62 (1991).

9. Heaver, T., Meersman, H., Moglia, F., and Voorde, E. V. D., "Do mergers and alliances influence European shipping and port competition?" Maritime Policy and Management, Vol. 27, No. 4, pp. 363-373 (2000).

10. Kadar, M. H. and DeProost, D., "Back to the 'basics' of marketing, pricing, and selling," Containerisation International, July, pp. 49-51 (1997).

11. Klir, G. J. and Yuan, B., Fuzzy Sets and Fuzzy Logic Theory and Application, Prentice-Hall (1995).
12. Lee, W. R., Chao, W. C., and Wu, M. C., "Partner selection determinants and alliance performance: an empirical study of Taiwan's information firms," Management Review, Vol. 19, No. 3, pp. 1-24 (2001).

13. Midoro, R. and Pitto, A., "A critical evaluation of strategic alliances in liner shipping," Maritime Policy and Management, Vol. 27, No. 1, pp. 31-40 (2000)

14. Robbins, S. P., Management, McGraw-Hill (1994).

15. Ryoo, D. K. and Thanopoulou, H. A., "Liner alliances in the globalization era: a strategic tool for Asian container carriers," Maritime Policy and Management, Vol. 26, No. 4, pp. 349-367 (1999).

16. Saaty, T. L., The Analytic Hierarchy Process, McGraw-Hill (1980).

17. Slack, B., Comtois, C., and McCalla, R., "Strategic alliances in the container shipping industry: a global perspective," Maritime Policy and Management, Vol. 29, No. 1, pp. 65-76 (2002).

18. Tang, S. M. and Lin, S. J., "Creating and verify the correlation model of strategy alliance management and performance," Journal of Management and Systems, Vol. 8, No. 1, pp. 37-60 (2001).

19. Yang, Y. C., "An interrelationship analysis on motivation and partner selection factors of liner strategic alliance across Taiwan Strait," Maritime Quarterly, Vol. 11, No. 2, pp. 89-112 (2002).

20. Zadeh, L. A., "Fuzzy sets," Information and Control, Vol. 8, No. 3, pp. 338-353 (1965). 